\title{
Multiple microscopic pulmonary arteriovenous connections in the lungs presenting as cyanosis
}

\author{
W MACNEE, TAS BUIST, NDC FINLAYSON, D LAMB, HC MILLER, AL MUIR, \\ AC DOUGLAS
}

From the Royal Infirmary, Edinburgh

Pulmonary arteriovenous fistulae have been well described in the published reports'; the right to left shunt produces arterial oxygen desaturation, cyanosis, finger clubbing, and murmurs over the lung fields. Most arteriovenous fistulae are relatively large and can be diagnosed by pulmonary angiography. ${ }^{\prime}$ Multiple small pulmonary arteriovenous fistulae, or telangiectasia, are rare, ${ }^{2}$ and usually occur in hereditary haemorrhagic telangiectasia (Osler-RenduWeber syndrome). Very rarely these fistulae are minute and may not be recognised by pulmonary angiography. ${ }^{3}$ The association between chronic liver disease and multiple pulmonary arteriovenous anastomoses is also well recognised. ${ }^{45}$

The patient reported here is unusual in that he presented with cyanosis and finger clubbing without apparent cause. A subsequent diagnosis of multiple minute arteriovenous fistulae was made on physiological and pathological grounds, with the later discovery of underlying juvenile hepatic fibrosis with aberrant connections between the systemic arterial and pulmonary venous circulations.

\section{Case report}

A 19 year old boy had first presented in 1977 aged 14 after his relatives had noticed that his lips had become blue in the preceding three months. He was symptom free, led a healthy and unrestricted life, and was a keen competitive sportsman. He gave no relevant family history. He was thin, of average height for his age, and deeply cyanosed and had gross finger clubbing. No other abnormality was noted on detailed systematic examination.

The haemoglobin was $15.0 \mathrm{~g} / \mathrm{dl}$ and the packed cell volume 0.43. No abnormal haemoglobin pigments were detected. Results of liver function tests and the electrocardiogram and chest radiograph were normal. Vital capacity was reduced ( $2.12 \mathrm{l}$, predicted $3.55 \mathrm{l})$. TLCO was reduced to $36 \%$ of the predicted value. Remaining lung volumes were normal. $\mathrm{PaO}_{2}$ was $7.7 \mathrm{kPa}(58 \mathrm{~mm} \mathrm{Hg}), \mathrm{PaCO}_{2} 4.0$ $\mathrm{kPa}(30 \mathrm{~mm} \mathrm{Hg}), \mathrm{pH} 7.48$. Right and left heart catheterisation, the latter via a patent foramen ovale, showed normal pressures and no evidence of an intracardiac shunt. Pulmonary angiography showed nothing was abnormal. Breathing $100 \%$ oxygen for 15 minutes produced on arterial oxygen saturation of $100 \%$ and $\mathrm{a} \mathrm{PaO}_{2}$ of $47.6 \mathrm{kPa}$ (357

Address for reprint requests: Dr W MacNee, Department of Medicine, Royal Infirmary, Edinburgh EH3 7YW.

Accepted 29 October 1984 $\mathrm{mm} \mathrm{Hg}$ ). A ventilation lung scan with xenon 131 was normal, as was the perfusion lung scan using technetium $99 \mathrm{~m}$ labelled macroaggregates (labelling efficiency 95\%) except that an outline of the kidneys was noted.

The patient remained symptom free but in 1978 developed splenomegaly confirmed by liver and spleen scintigraphy. The liver was small but showed a normal distribution of isotope. The serum bilirubin concentration was now raised at $22 \mathrm{mmol} / \mathrm{l}(1.29 \mu \mathrm{g} / 100 \mathrm{ml})$, as was the alkaline phosphatase activity at 240 units/l, which was due to bone isoenzyme; alanine aminotransferase was normal. Laparoscopic liver biopsy confirmed an enlarged spleen and a small liver. The histological appearances of the liver were compatible with very mild portal fibrosis.

As there was no definite cause for this young man's cyanosis an open lung biopsy (lingula) was performed and histological examination was considered initially to show mild non-specific scarring with a histiocytic infiltrate and occasional lymphocytes and plasma cells in the lung stroma. The features were non-specific and not diagnostic.

The patient remained well but, because the diagnosis was uncertain, further cardiac catheterisation was performed in 1980, which again showed no evidence of an intracardiac shunt. Pulmonary angiography showed nothing abnormal. When the patient was at rest breathing $100 \%$ oxygen full arterial oxygen saturation could be achieved; appreciable desaturation to $60 \%$ was induced by exercising when breathing air, however, and this could not be fully corrected when he breathed $100 \%$ oxygen. A further radionuclide examination was performed with ${ }_{94 \mathrm{~m}} \mathrm{Tc}$ labelled microspheres. There was no evidence of an intracardiac shunt but activity was detected in the left ventricle after passage through the lungs (fig 1). Shortly afterwards considerable activity was detected in the kidneys and brain. As labelling efficiency was $98 \%$ the passage through the lungs indicated intrapulmonary "shunting" or passage through vessels with a diameter greater than 30 (fig 1). Because of these findings the lung biopsy material was re-examined. Leashes of vessels running into the alveolar walls were seen (fig 2). The vessels were excessive in size, diameter, and number, consistent with minute arteriovenous fistulae. If such vessels were present diffusely throughout the lungs, they would explain the clinical picture.

In 1982 the patient became dyspnoeic on exercise and developed polycythaemia ( $\mathrm{Hb} 17.3 \mathrm{~g} / \mathrm{dl}$; red cell mass $\mathbf{0 . 4 9}$ $1 / \mathrm{kg}$ (normal range $0.027-0.035 \mathrm{lkg}$ )). There were no new clinical findings. The arterial $\mathrm{PaO}_{2}$ was now $5.9 \mathrm{kPa}(44.2$ $\mathrm{mm} \mathrm{Hg}$ ) and pulmonary arterial pressure was again normal. 


\section{Radioactive Counts \\ as $\%$ Peak Activity}

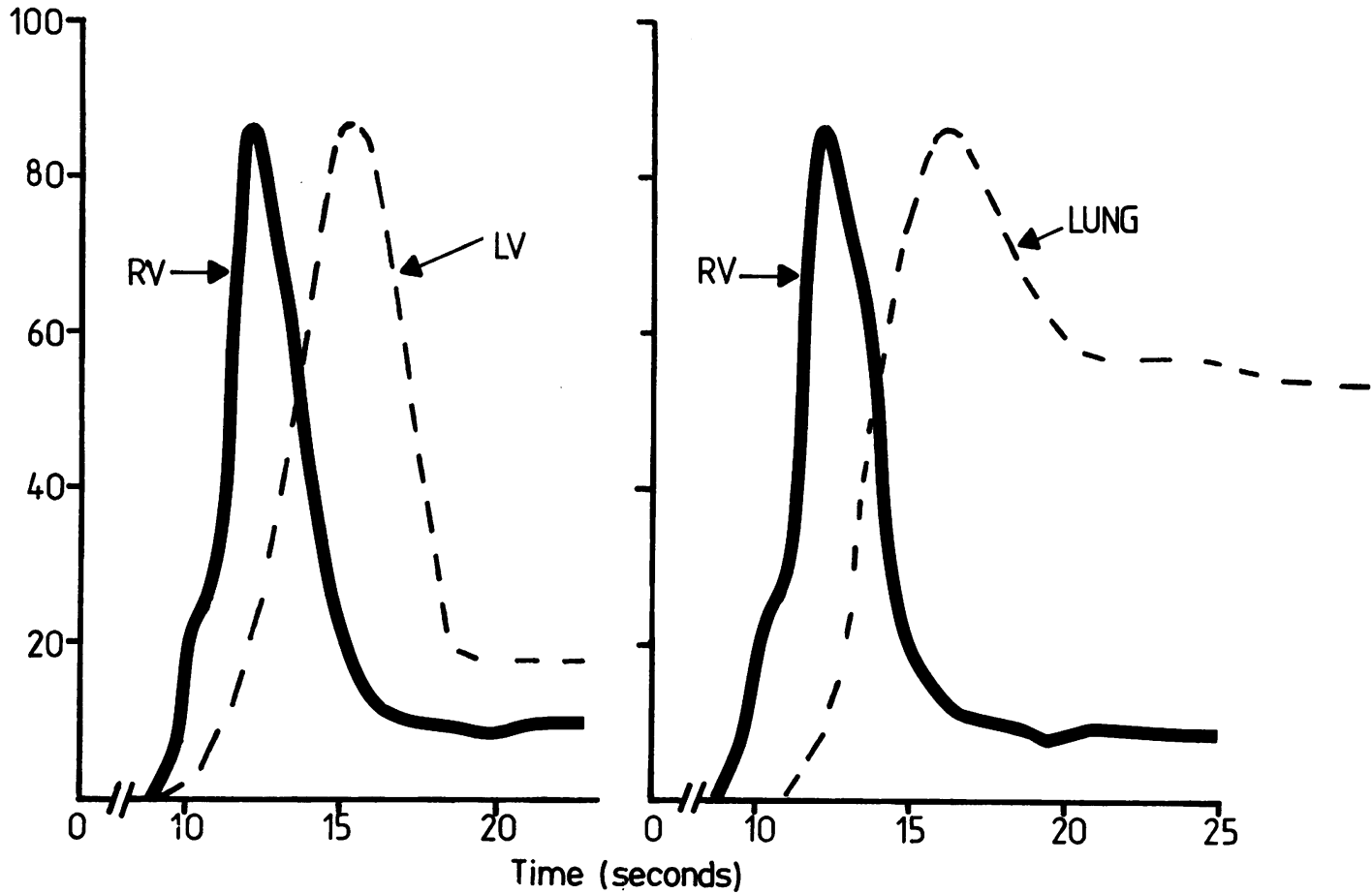

Fig 1 Right ventricular (RV) and left ventricular ( $L V$ ) curves contrasted after the same intravenous bolus of $40 \mathrm{MBq}$ of technetium $99 \mathrm{~m}$ labelled microspheres. Activity is seen in the left ventricle but there is no early appearance as would be seen in an intracardiac shunt. The curve from the right ventricle is normal. In the lung if all the microspheres had impacted there would be no reduction in radioactivity and a plateau would have been achieved. In this case there was considerable loss of radioactive counts before a plateau was achieved, suggesting that a proportion of microspheres had entered the lung but had not lodged. Similar curves were obtained from upper middle and lower zones of both lungs.

As the liver biopsy in 1977 had shown mild portal fibrosis, the serum bilirubin was now raised at $42 \mathrm{mmol} / \mathrm{l}$ $(2.46 \mu \mathrm{g} / 100 \mathrm{ml})$, and there was spenomegaly and evi-

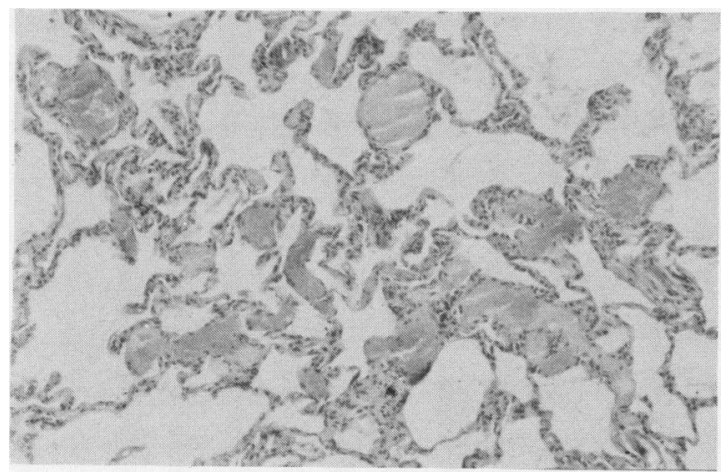

Fig 2 Open lung biopsy material. Dilated, thin walled, telangiectatic vessels are shown lying in the walls of alveoli. dence in the peripheral blood of hypersplenism, an assessment of liver haemodynamics was carried out. Portal venous pressure was raised $(260 \mathrm{~mm}$ saline) with a normal wedged hepatic venous pressure. Contrast injected in to the splenic vein showed normal splenic blood flow with patent hepatic and portal veins. Coeliac and mesenteric angiography showed appreciable splenomegaly with a small liver and without oesophageal varices. These results indicate intrahepatic, presinusoidal portal hypertension, consistent with the diagnosis of congenital hepatic fibrosis. Finally, anomalous supply to the pulmonary veins was noted from a branch of the left gastric artery and from an enlarged inferior phrenic artery.

The effect of oxygen on the patient's dyspnoea was compared in blind fashion at a flow rate of $3 \mathrm{l} / \mathrm{min}$ via nasal cannulas at rest and during exercise. Arterial oxygen saturation rose from $68 \%$ to $91 \%$, and $\mathrm{PaO}_{2}$ from 5.1 to 8.8 $\mathrm{kPa}(38$ to $66 \mathrm{~mm} \mathrm{Hg}$ ) when breathing oxygen at rest. The 12 minute walking distance increased from 576 to 650 metres when the patient breathed oxygen. He has been supplied with portable liquid domiciliary oxygen to be used 
continuously both at home and while at training college and he has remained in a stable state for two years.

\section{Discussion}

We have been able in this case to diagnose multiple minute pulmonary arteriovenous anastomoses on both physiological and pathological grounds. This is a great rarity, for although there have been many reports of arteriovenous fistulae only 20 cases of multiple small arteriovenous fistulae have been described. ${ }^{36-8}$ Most have been visualised by pulmonary angiography, and in only four previously reported cases has the angiogram been normal as in our case. Breathing of $100 \%$ oxygen failed to reveal a right to left shunt in our patient. This method has been shown to underestimate the size of the shunt in patients with larger multiple pulmonary arteriovenous anastomoses ${ }^{6}$ since, in contrast to air breathing, at high oxygen tensions the abnormal vessels can take part in gas exchange. The use of injected radioisotope labelled microspheres showed in our case intrapulmonary shunting in all regions of the lungs and has helped in the diagnosis in two previously reported cases. ${ }^{67}$ We had, however, additional pathological confirmation of the diagnosis in life.

A further feature of this case is the presence of liver disease, which can also produce cyanosis ${ }^{4}$ and pulmonary arteriovenous fistulae. ${ }^{5}$ Arterial desaturation associated with liver disease is usually slight, ${ }^{5}$ even in the most severely cirrhotic patients. Our patient had mildly impaired liver function and moreover presented with appreciable hypoxaemia before any liver dysfunction was present, making a causal association between the two unlikely.

The abberant connections between intra-abdominal arteries and pulmonary veins may have resulted from the development of cirrhosis, or arisen as a consequence of the pulmonary telangiectasia, but they could not have contributed appreciably to the hypoxaemia.

\section{References}

1 Sanders JS, Martt JM. Multiple small pulmonary arteriovenous fistulae. Circulation 1962;25:383-9.

2 Tobin CE. Arteriovenous shunts in the peripheral pulmonary circulation in the human lung. Thorax 1966;21:197-204.

3 Moyer JH, Glantz G, Brest AN. Pulmonary arteriovenous fistulae; physiologic and clinical considerations. Am J Med 1962;32:417.

4 Berthelot P, Walker JG, Sherlock S, Reid L. Arterial changes in the lungs in cirrhosis of the liver-lung spider nevi. $N$ Engl $J$ Med 1966;272:291-8.

5 Karlish AJ, Marshall R, Reid L, Sherlock S. Cyanosis with hepatic cirrhosis. Thorax 1967;22:555-61.

6 Genovesi MG, Tierney DF, Tapline GV, Eisenberg H. An intravenous radionuclide method to evaluate hypoxaemia caused by abnormal alveolar vessels. Am Rev Dis 1976; 114:59-65.

7 Currarino G, Willis KW, Johnson AF, Miller WN. Pulmonary telangiectasia. Am J Roentgenol 1976;127:775-9.

8 Charles TJ, Davies AB. Pulmonary telangiectasis. $\mathrm{Br} J \mathrm{Dis}$ Chest 1979;73:309-13. 